\title{
EOSINOFILORRAQUIA EM PROCESSOS INFLAMATORIOS DO SISTEMA NERVOSO CENTRAL E SEUS ENVOLTORIOS
}

\author{
L. R. MACHADO* \\ J. A. LIVRAMENTO * \\ A. IPINA-FRAN QA **
}

As reações inflamatórias leptomeningeas sinalizadas por eosinófilos constituem um modo peculiar de resposta no sistema nervoso central (SNC) ocorrendo em patologias inflamatórias, desmielinizantes, tumorais e vasculares $\mathbf{1 , 8}$.

A fisiopatologia do eosinófilo obedece a causalidade final diversa, em função de fatores imunológicos próprios a cada doença ${ }^{5}$. Existem vários mecanismos de migração de eosinófilos até ao sistema nervoso, devendo ser destacados, além dos mecanismos inespecificos de natureza alérgica, aqueles resultantes da ativação do complemento e os mediados por linfocinas específicas $3,7,15$. Existe, portanto, um plano de defesa imunológico incluindo eosinófilos que transcende o do epifenômeno ou o do efeito colateral não desejado e, eventualmente, nocivo.

Processos virais, de natureza fugaz e evoluçăo benigna, constituem um modelo monofásico de reação inflamatória com eosinofilorraquia. Por cutro lado, a cisticercose do SNC constitui um modelo de sinalização inflamatória repetitiva, com eosinófilos ${ }^{10,12}$, fazendo parte da sindrome da neurocisticercose 4 . Os escassos recursos terapêuticos disponiveis até há pouco tempo preservaram a evolução natural da doença, com respostas potencializadas por episódios anteriores e obedecendo a memória imunológica em diversos graus de ativação, resultando em imunoagressão de intensidade crescente ${ }^{13}$. Tal modelo ganhou consistência prática com o uso do Praziquantel, derivado pirazino-isoquinoleínico de introdução recente na terapêutica medicamentosa ${ }^{14}$. Surgiu, assim, a possibilidade de provocar uma alteração no ciclo vital do parasita com resposta inflamatória associada, detectável clínica e laboratorialmente. Anıbos os modelos pressupõem eventos etiopatogênicos diversos, mas apresentam resposta fenomelogicamente semelhante.

O critério analítico escolhido é o comportamento do dual citoproteico do líquido cefalorraqueano (LCR). Alterações no contingente celular e no contingente proteico ${ }^{10}$ correspondem a modos distintos de disfunção do complexo barreira hêmato-LCR, durante a resposta inflamatória. Por serem duas expressões do mesmo fenômeno, apresentam inter-relações em diversos niveis. Ambos os contingentes podem e devem ser conceituados como um dual em que as

\footnotetext{
Trabalho do Centro de Investígaçoes em Neurologia da Faculdade de Medicina da Universidade de são Paulo: * médico assistente; ** professor adjunto. Apresentado ao 90 Congresso Brasileiro de Neurologia (Ciritiba - outubro, 1980).
} 
informações não se superpõem, mas traduzem aspectos e variantes com diferentes graus de responsabilidades na interpretação global 12.

O objetivo deste trabalho é estudar o comportamento do dual citoproteico do LCR nos dois modelos de sinalização e analisar suas possiveis correlações.

\section{MATERIAL E METODOS}

A análise do comportamento do dual citoproteico do LCR fol felta em 45 pacientes em vigencia de processo inflamatório do SNC sinalizado por eosinófilos.

O primeiro grupo compð̌e-se de 35 pacientes com reaçð̃es imunológicas năo reagentes e dados clínicos e de evolução que permitem sua classificação como processos virais. Os pacientes situavam-se numa faixa etária entre 10 e 62 anos, e o tempo de evolução da doença variou de 3 a 8 dias.

O segundo grupo é constituído de 10 pacientes com reações imunológicas reagentes para cisticercose e que foram submetidos a tratamento com Praziquantel 14, escolhidos aleatoriamente dentre a população acometída pela doença. A fajxa etária variava entre 7 e 66 anos. Nenhum dos pacientes fol submetido a corticoterapia na época do estudo.

O material fol obtido mediante punçăo sub-occipital. A contagem global de células fol feita em cAmara tipo Fuchs-Rosenthal. O sedimento para citomoriologia fol preparado mediante o uso da camara de sedimentação gravitacional acelerada de Suta. Os preparados assim obtidos foram corados pelo método de Leishman. $O$ exame citomorfológico fol realizado mediante optomicroscopia. Os dados do proteinograma foram obtidos mediante técnica padronizada em nosso melo 0,11 . O citoproteinograma do LCR fol classificato em sub-grupos segundo os critérios clássicos 11.

A análise estatística fol feita mediante a transformaçáo logarítmica das varíávels. Tal procedimento se justifica pela presença de desvios-padrăo com razåo constante e em funçăo da distrib:içăo normal das variáveis transformadas. A análise comparativa entre os grupos 2 obedeceu à padronização requerida para o teste $t$ de Student, com $\alpha=0,1$.

\section{RESULTADOS}

Verificada concordancia, por análise de confronto, do comportamento do dual nos dols grupos, fol considerada, primeiramente, cada determinaça come evento isolado, analisando tal concordancia. Em segundo lugar, fol feita análise evolutiva no grupo da cisticercose do SNC já que, na meningite viral, por ocorrer evento monofásico e fugaz, não é poşível tal tipo de abordagem.

Nas Tabelas 1, 2 e 3 estão resumidos os resultados comparativos dos dois grupos de patologias. Dentro dos critérios estatísticos estabelecidos previamente, fol verificado năo haver diferença significativa entre os valores obtidos para citologia global, eosinofilorraquia, e proteinas totais em meningites virais e em cisticercose do SNC. Na Tabela 4 estão resumidos os valores das globulinas gama.

Em relaçăo ao comportamento evolutivo do dual citoproteico na cisticercose, foi constatada relaço constante do evento inflamatório com a terapia utilizada nos 10 casos. 
Resultam 20 episódios de comportamento análogo. Tais episódios podem apresentar 3 tipos de sequencia: 1) o segundo episódio é semelhante ao primeiro (3 casos); 2) o segundo episódio é diferente do primeiro, ocorrendo intensidade de fenómenos maior no segundo episódio (3 casos) e ocorrendo intensidade maior de fenómenos no primeiro episódio (1 caso); 3) dissociação de intensidade na resposta citoproteica com aumento da resposta gama no segundo episódio (3 casos).

\begin{tabular}{|c|c|c|c|c|}
\hline \multirow[b]{2}{*}{$f(x)$} & \multicolumn{3}{|c|}{ Pleocitose } & \multirow[b]{2}{*}{$\begin{array}{c}\text { Nitida } \\
\mathbf{2 , 3 1 - 3 , 0 0}\end{array}$} \\
\hline & $\begin{array}{l}\text { Ligeira } \\
\text { até } 1,00\end{array}$ & $\begin{array}{l}\text { Discreta } \\
1,01-1,07\end{array}$ & $\begin{array}{c}\text { Moderada } \\
1,71-2,30\end{array}$ & \\
\hline \multirow[t]{3}{*}{ Meningite a virus } & & $n=10$ & $n=9$ & $\mathrm{n}=16$ \\
\hline & & $\bar{x}=1,37$ & $\bar{x}=2,04$ & $\bar{x}=2,62$ \\
\hline & & $\mathbf{s}=0,23$ & $\mathrm{~s}=\mathbf{0 , 1 6}$ & $s=0,17$ \\
\hline \multirow[t]{3}{*}{ Cisticercose do SNC } & $n=5$ & $\mathrm{n}=25$ & $\mathrm{n}=31$ & $\mathrm{n}=12$ \\
\hline & $\bar{x}=0,87$ & $\bar{x}=1,39$ & $\bar{x}=1,95$ & $\bar{x}=2,59$ \\
\hline & $\mathrm{s}=0,06$ & $s=0,28$ & $\mathrm{~s}=0,18$ & $s=0,15$ \\
\hline
\end{tabular}

Tabela 1 - Citologia global: $x=$ numero de ḉlulas/mms; $n=$ número de amostras; $\bar{x}-$ média; $s=$ desvio padrdo; $f(x)=\log x$.

\begin{tabular}{|c|c|c|c|}
\hline \multirow[b]{2}{*}{$f(x)$} & \multicolumn{3}{|c|}{ Proteinorraq :ia total } \\
\hline & $\begin{array}{l}\text { Normal } \\
\text { até } 1,48\end{array}$ & $\begin{array}{c}\text { Aumento discreto } \\
1,49-1,70\end{array}$ & $\begin{array}{c}\text { Aumento moderado } \\
1,71-2,30\end{array}$ \\
\hline \multirow[t]{3}{*}{ Menigite a virus } & $\mathbf{n}=\mathbf{5}$ & $\mathrm{n}=15$ & $\mathrm{n}=15$ \\
\hline & $\vec{x}=1,32$ & $\vec{x}=1,58$ & $\bar{x}=1,87$ \\
\hline & $\mathrm{s}=0,03$ & $\mathbf{s}=0,06$ & $\mathbf{s}=0,17$ \\
\hline \multirow[t]{3}{*}{ Cisticercose do SNC } & $\mathrm{n}=20$ & $n=20$ & $\mathrm{n}=33$ \\
\hline & $\vec{x}=1,42$ & $\vec{x}=1,60$ & $\bar{x}=1,85$ \\
\hline & $s=0,06$ & $\mathbf{s}=0,06$ & $\mathbf{s}=0,12$ \\
\hline
\end{tabular}

Tabela 2 - Proteinorraquia total: $x=$ concentracáo proteica em $m g / 100 \mathrm{ml} ; n=$ amostras; $\bar{x}=$ média; $s=$ desvio padrdo; $f(x)=\log x$. 


\begin{tabular}{|c|c|c|c|c|c|}
\hline \multirow[b]{2}{*}{$f(x)$} & \multicolumn{5}{|c|}{ Eosinofilorraquia } \\
\hline & $\begin{array}{l}\text { Ligeira } \\
\text { até } 1,00\end{array}$ & $\begin{array}{l}\text { Discreta } \\
1,00-1,70\end{array}$ & $\begin{array}{l}\text { Moderada } \\
\mathbf{1 , 7 1 - 2 , 3 0}\end{array}$ & $\begin{array}{c}\text { Nitida } \\
\text { 2.31-3,00 }\end{array}$ & $\begin{array}{l}\text { Intensa } \\
\text { acims } \\
\text { de } 3,00\end{array}$ \\
\hline \multirow[t]{3}{*}{ Meningite a virus } & $n=6$ & $\mathrm{n}=15$ & $\mathbf{n}=\mathbf{9}$ & $n=3$ & $\mathbf{n}=\mathbf{3}$ \\
\hline & $\bar{x}=0,60$ & $\vec{x}=1,30$ & $\bar{x}=2,07$ & $\bar{x}=2,49$ & $\bar{x}=3,31$ \\
\hline & $s=0,25$ & $\mathrm{~s}=0,25$ & $\mathrm{~s}=0,17$ & $s=0,17$ & $\mathrm{~s}=0,26$ \\
\hline \multirow[t]{3}{*}{ Cisticercose do SNC } & $n=12$ & $n=26$ & $n=10$ & $n=13$ & $\mathrm{n}=8$ \\
\hline & $\vec{x}=0,55$ & $\bar{x}=1,36$ & $\bar{x}=2,02$ & $\bar{x} \leftrightharpoons 2,55$ & $\bar{x}=3,34$ \\
\hline & $\mathrm{s}=0,29$ & $\mathrm{~s}=0,20$ & $s=0,20$ & $s=0,21$ & $\mathrm{~s}=0,16$ \\
\hline
\end{tabular}

Tabela 3 - Eosinofilorraquia: $x=$ namero de eosinofilos por cms; $n=$ numero de amostras; $\bar{x}=$ média; $8=$ desvio padräo; $f(x)$ log $x$.

\begin{tabular}{|c|c|c|c|c|}
\hline \multirow[b]{2}{*}{$f(x)$} & \multicolumn{4}{|c|}{ Gamaglobulinorraquia } \\
\hline & $\begin{array}{l}\text { Normal } \\
\text { até } 0,62\end{array}$ & $\begin{array}{c}\text { Aumento } \\
\text { discreto } \\
0,63-1,02\end{array}$ & $\begin{array}{c}\text { Aumento } \\
\text { moderado } \\
1,03-1,18\end{array}$ & $\begin{array}{l}\text { Alumento } \\
\text { nitido } \\
\text { acima } \\
\text { de } 1,18\end{array}$ \\
\hline \multirow[t]{3}{*}{ Cisticercose do SNC } & $n=10$ & $\mathrm{n}=26$ & $\eta=10$ & $n=26$ \\
\hline & $x=0,57$ & $x=0,81$ & $x=1,14$ & $x=1,45$ \\
\hline & $\mathrm{s}=0,08$ & $\mathbf{s}=0,09$ & $\mathbf{s}=0,05$ & $\mathrm{~g}=0,19$ \\
\hline
\end{tabular}

Tabela \& - Gamaglobulinorraquia: $x=$ concentragdo em $\mathrm{mg} / 100 \mathrm{ml} ; n=$ número de amostras; $\bar{x}=$ média, $8=$ desvio padrāo; $f(x)=\log x$.

\section{COMBNTARIOS}

Os resultados permitem afirmar que, nos casos estudados, ccorreu resposta harmônica dos elementos do dual em ambos os modelos inflamatórios considerados. A análise isolada de eventos mostra concordância de tipo e intensidade de resposta nos processos virais e na cisticercose de SNC. A análise sequencial nesta última patologia mostra a possibilidade de sinalizar o dual através do uso de medicação específica. As diferenças entre o primeiro o segundo episódios podem não depender da resposta do sistema em si. Não pode ser excluída a influência de outros fatores como, por exemplo, número variável de cisticercos ainda viáveis no segundo episódio, determinando graus diversos de respostas. 
A ocorrência de dissociação num dual previamente sinalizado em 3 pacientes, com aumento desproporcional do contingente gama no segundo episódio pode confirmar os estudos anteriores sobre imunoagressão em pacientes com episódios inflamatórios repetidos ${ }^{\text {,14. }}$. Tal fato sugere, em fase tardia da doença, mudança qualitativa das respostas imunológicas. Esta mudança, no entanto, pressupõe uma fase em que a resposta repetitiva é apenas a reprodução de uma resposta monofásica. Cria-se, assim, a possibilidade e a oportunidade de agressão medicamentosa ao parasita, sem maiores danos imunológicos ao paciente que os representados por um processo inflamatório viral.

\section{RESUMO}

O comportamento do dual citoproteico do LCR é instrumento adequado para a compreensão e o acompanhamento evolutivo de processos inflamatórios do sistema nervoso central.

O surto inflamatório sinalizado por eosinófilos na cisticercose do sistema nervoso central é semelhante, quantitativa e qualitativamente, ao que ocorre em processos inflamatórios monofásicos de etiologia viral. No entanto, pode ocorrer dissociação de comportamento das globulinas gama, gradativa e persistentemente aumentadas com relação ao citoproteinograma clássico. Tal fato pode ser expressão de imunoagressão semelhante à que ocorre em processos inflamatórios do sistema nervoso central com componente autoimune, como a neurossifilis e a esclerose múltipla.

\section{SUMMART}

Eosinophil cells in the cerebrospinal fluid in inflammatory diseases of the central nervous system and its leptomeningeal coverings.

Eosinophil cells play an important role in the signalization of cerebrospinal fluid (CSF) by inflammatory diseases of central nervous system and its leptomeningeal coverings (CNS), according to present data on neuroimmunology. The extent of their participation in local immunological phenomena is evaluated, and data on other changes in the CSF cytoprotein dual were considered for comparative purposes.

CSF of two types of inflammatory diseases of the CNS were studied for this purpose: samples of 35 patients in early stages of acute eosinophilic leptomeningites possibly of viral origin (first group) and 20 samples of 10 patients with neurocysticercosis (second group).

Samples of the second group were collected in the early stages of each one of two episodes of exhacerbation in the inflammatory reaction observed at each one of the two series of administration of Praziquantel, a pirazino-isochinoleinic derivate which action upon cysticerci has been reported.

Statistical analysis shows that participation of eosinophil cells in the inflammatory response does not differ in the two groups. Their participation 
is related to changes observed in the CSF cytoprotein dual rather than to the type of the inflammatory model: acute and monophasic in the first group, and chronic and repetitive in the second.

Gamma globulins participe in the exhacerbation of CSF inflammatory reaction in neurocysticercosis but their behaviour not always is similar. In some instances it is similar to that found in other chronic and repetitive inflammatory models, as multiple sclerosis for instance.

\section{REFERENCIAS}

1. BOSCH, I. \& OEMICHEN, M. - Eosinophillic granulocytes in cerebrospinal fluid: analysis of 94 cerebrospinal fluid specimens and review of the literature. Neurology (Minneapolis) 219:93, 1978.

2. DIXON, W. J. \& MASSEY, F. J. - Introduction to Statistical Analysis. International Student Edition, Tokyo, 1969.

3. LAGRANGE, P. H. \& CAPRON, A. - Immune responses directed againgt infections and parasitic agents. Iro Bach, J. F., ed. - Immunology. John Wlley \& Sons Inc, New York, 1978, pg. 410-444.

4. LANGE, O. - Sindromo liquórico da cisticercose encéfalo-meningéla. Rev. Neurol. Pạlquiat. (Săo Paulo) 6:35, 1940.

5. LIVRamento, J. A. - Contribuiçáo de reaçós de imunofluorescencia no liquido cefalorraqueano no estudo da neurocisticercose. Tese. Fac. Med. Univ. Săo Paulo, 1980.

6. LUTZ, W. - Statistical methods as applied to immunological data In Weir, D. M., ed. - Handbook of Experimental Immunology. Blackwell Bcient. Publ., Oxford, 1979, pg. A2.1.

7. MARTINEZ-CAIRO; 8. C.; FRATI, A. M. \& ESPINOSA, J. A. - Biologia del esosinófilo. Prensa mód. mex. (México) 43:3, 1978.

8. SPINA-FrANCA, A. - Cisticercose do sistema nervoso central: consideraçes sobre 50 casos. Rev. paul. Med. 48:59, 1956.

9. SPINA-FRANCA, A. - Valor do exame eletrofético das proteinas do liquido cefalorraqueano na cisticercose do SNC. Tese. Fac. Med. Univ. São Paulo, 1960.

10. SPINA-FRANCA, A. - Imunobiologia da claticercose: avaliaçăo dos conceitos atuais. Arq. Neuro-Psiquiat. (São Paulo) 27:125, 1969.

11. SPINA-FraNCA, A. - Líquido Cefalorraqueano. In Tolosa, A. \& Canelas, H. M. - Propedéuetica Neurológica. Fundo Edit. Procienx, Ed. 2, são Paulo, 1971, pg. 443.

12. SPINA-FRANCA, A. - Sinalização de processos infecciosos do sistema nervoso. Rev. Med. (SĂo Paulo) 61:32, 1977.

13. SPINA-FRANCA, A.; LIVRAMENTO, J. A.; NOBREGA, J. P. S.; MACHAdO, L. R. \& SCHNAPP, M. - Long term evolution of the pathology of cerebrospinal fluid globulins in cysticercosis of the central nervous system: a comparison with data in neurosyphilis and multiple sclerosis. Excerpta med. internat. Congr. Ser. 427:180, 1977.

14. SPINA-FRANCA, A. \& NOBREGA, J. P. S. - Neurocisticercose e Praziquantel. Rev. paul. Med. 95:34, 1980.

15. WELLER, P. F. \& GOETZL, E. J. - The regulatory and effector roles of eosinophils. In Kunkel, H. G. \& Dixon, F. J., eds - Advances in Immunology. Academic Prerr, New York, 1979, pg. 339.

Sdo Paulo - Caixa Postal 5199 - 01000 sao Paulo, SP - Brasil.

Centro de Investigasóes em Neurologia - Fraculdade de Medicina, Universidade de 